Article

\title{
Urban Green Spaces and Housing Prices: An Alternative Perspective
}

\author{
Veronika Liebelt $1,2,3, * \mathbb{C}$, Stephan Bartke ${ }^{4(\mathbb{D})}$ and Nina Schwarz ${ }^{1,5}$ (i) \\ 1 Department Computational Landscape Ecology, Helmholtz Centre for Environmental Research-UFZ, \\ Permoserstraße 15, 04318 Leipzig, Germany \\ 2 German Centre for Integrative Biodiversity Research (iDiv) Halle-Jena-Leipzig, Biodiversity Economics, \\ Deutscher Platz 5e, 04103 Leipzig, Germany \\ 3 Faculty of Economics and Management Science, Institute for Infrastructure and Resources Management, \\ Leipzig University, Grimmaische Straße 12, 04109 Leipzig, Germany \\ 4 Department of Economics, Helmholtz Centre for Environmental Research-UFZ, Permoserstraße 15, \\ 04318 Leipzig, Germany \\ 5 Faculty of Geo-Information Science and Earth Observation (ITC), University of Twente, \\ 7500 AE Enschede, The Netherlands \\ * Correspondence: veronika.liebelt@ufz.de; Tel.: +49-341-9733-162
}

Received: 22 May 2019; Accepted: 3 July 2019; Published: 6 July 2019

check for updates

\begin{abstract}
Urban green spaces (UGS) are essential components of sustainable cities that provide many benefits to urban residents, such as recreation or aesthetics. Urban residents may be willing to pay for some of these ecosystem services. Indeed, studies investigating the formation of housing prices through hedonic pricing analysis have shown that UGS can influence housing prices. Hedonic pricing analysis puts housing units at the center of analysis. In this study, we investigate whether an alternative perspective provides additional insights into the effects of UGS on pricing. The proposed approach puts UGS into the center of analysis by applying an analysis of buffer zones to housing prices, thus, linking approaches from urban economics and landscape ecology. Such an analysis could deepen our understanding of the effects of UGS on housing prices by analyzing price-distance slopes around UGS-thus supporting more informed decisions on efficient UGS management and urban planning. Our results using a case study on Leipzig, Germany, demonstrate that the size of UGS affects price-distance slopes around them. We conclude that further investigations should be fathomed to unleash the potential of applying the analysis of buffer zones around UGS as a method to inform sustainable UGS design in cities.
\end{abstract}

Keywords: urban green spaces; valuation; buffer zones; hedonic pricing; real estate

\section{Introduction}

Urbanization is a global trend resulting in the rapidly growing urban population [1]. There is a significant number of factors that determine the values of housing properties in cities such as characteristics of housing and neighborhood (e.g., the presence of child care centers, schools, hospitals, level of crime, etc.), distance to the central business district and places of work. Hectic lifestyles, limited space for rest and mental and physical recovery, turn modern cities into stressful places of living [2]. Urban green spaces (UGS) provide valuable ecosystem services to residents, i.e., deliver "benefits people obtain from ecosystems" [3] (see also the broader perspectives of Daily (1997) or Constanza et al. (1997) [4,5]). The concept of ecosystem services broadly entails the services which are actually perceived, appreciated and valued by humans, such as recreational opportunities, aesthetic enjoyment, water retention and purification, and microclimate regulation (i.e., cooling effect) for cities [1]. 


\subsection{Hedonic Pricing Analysis of UGS}

Hedonic pricing analysis is one method to valuate those ecosystem services that residents perceive and appreciate. Hedonic pricing analysis works under the assumption that urban residents may be willing to pay for some of the ecosystem services provided by UGS since housing prices implicitly reflect the extent to which a variety of amenities, including ecosystem services, are appreciated in certain locations [6]. Thus, many studies have investigated their relationship with real estate prices [4,5,7-21]. Hedonic pricing analysis is the most commonly applied approach for such investigations. Technically, this means explaining the price of a housing unit by considering UGS-related variables, for example, distance to the next UGS or share of UGS in the vicinity together with other relevant variables. Whereas, this approach is straight forward to analyze, it also faces a disadvantage: the spatial distribution of UGS in a city can hamper the analysis of UGS as one of the several elements influencing housing prices [22-24].

For instance, in a city with numerous small and dispersed and a few large UGS, the closest UGS to a given housing unit is more likely to be small. Thus, the effects of the larger UGS may be underestimated in a classical hedonic approach if merely considering the nearest UGS, because price effects will only be quantified for the proximal housing units. This might lead to methodological artefacts and blur the effects of specific characteristics of UGS on prices.

We illustrate this potential effect in a thought experiment (Figure 1) for a specific case: Assuming, we value the impact of UGS on the price of the housing unit located at 9th Avenue and 57th Street in central Manhattan, New York City. When using distance as an indicator of the relevant UGS, this property is linked to Baisley Park-although the dwellers are likely to emphasize that their location is proximal to New York's famous Central Park. Our example indicates the following: The closest UGS is not necessarily the most relevant one for the inhabitants. There are situations in which residents do not prefer the nearest UGS compared with one farther away, for example, due to easier accessibility, size or other features.

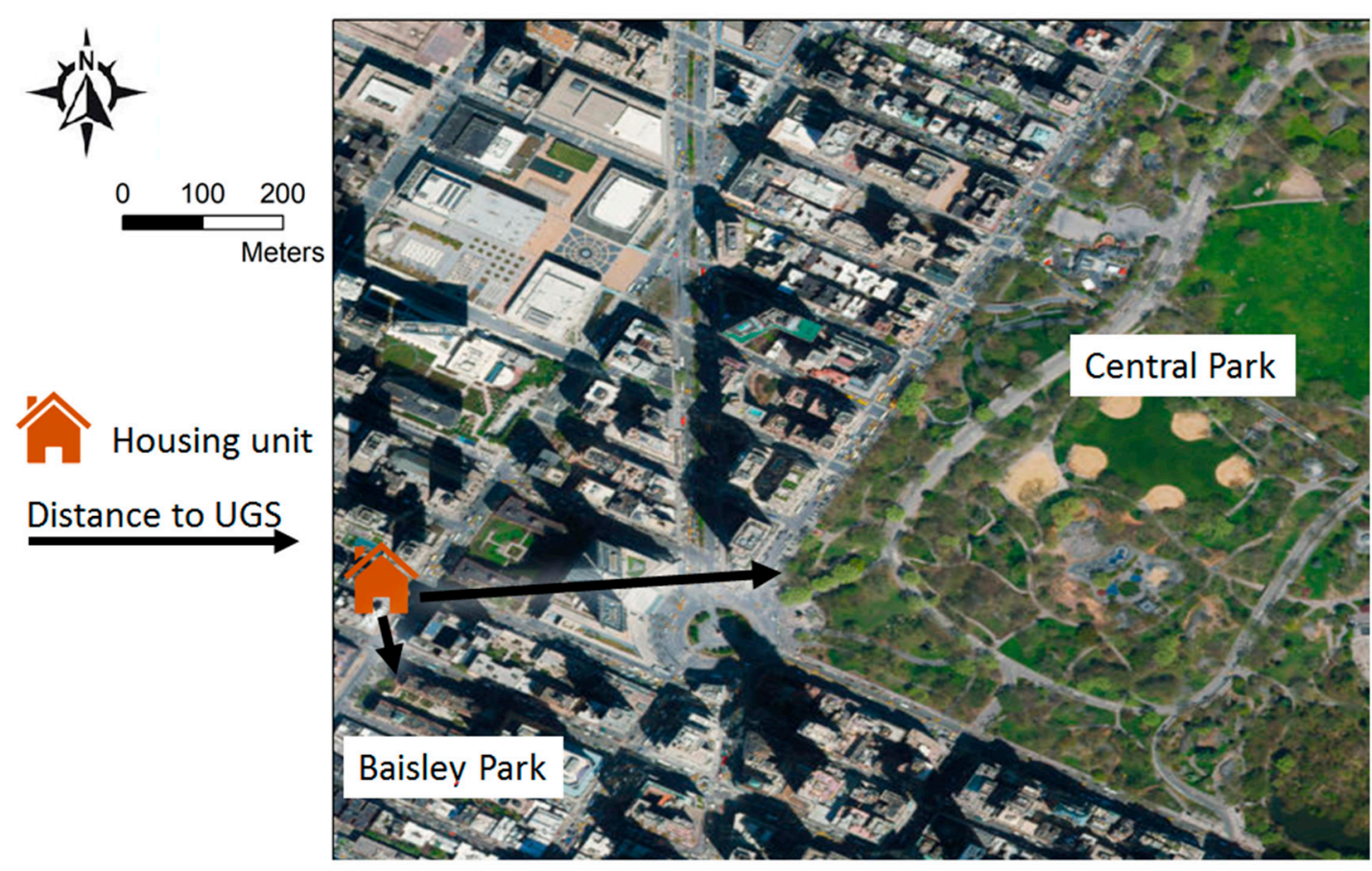

Figure 1. A thought experiment: the closest UGS may not be the most relevant. (ESRI aerial imagery basemap, 2019). 


\subsection{Gradient Analysis in Landscape Ecology}

Putting the UGS into the center of analysis could help to disentangle the effects of different UGS. One approach to do so is the analysis of buffer zones around UGS as commonly performed in landscape ecology. Urban-to-rural gradients can be analyzed for the assessment of ecosystem service provision [1], changes of landscape patterns [25], urban expansion [26-28], or changes in UGS structure $[29,30]$. In contrast to gradients from the central business district (CBD), gradients from UGS have been employed, for instance, to investigate their cooling effect [31-33]. Thus, the analysis of buffer zones around UGS tests whether gradients going away from this UGS exist with respect to a certain variable. In doing so, the impact of this UGS onto the surroundings is investigated.

\subsection{An Alternative Perspective of Analysing UGS Effects on Prices}

We propose to investigate if both methodologies can be linked in order to exploit their advantages: hedonic pricing offering a hands-on, easy to communicate monetary assessment of the value contributed by various characteristics (e.g., features of UGS), and analysis of buffer zones offering spatial insight into the impact analysis centered around the UGS. We suggest a combination of both in a way that housing prices are analyzed while putting UGS at the center of this investigation as it is demonstrated in Figure 2. This figure visualizes how a hedonic pricing approach (a) differs from our proposed approach (b).

(a)

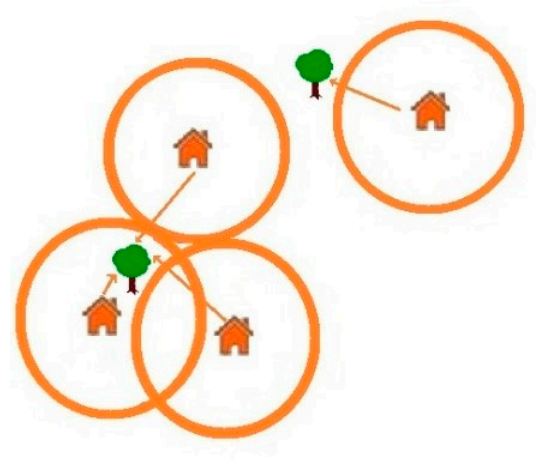

(b)

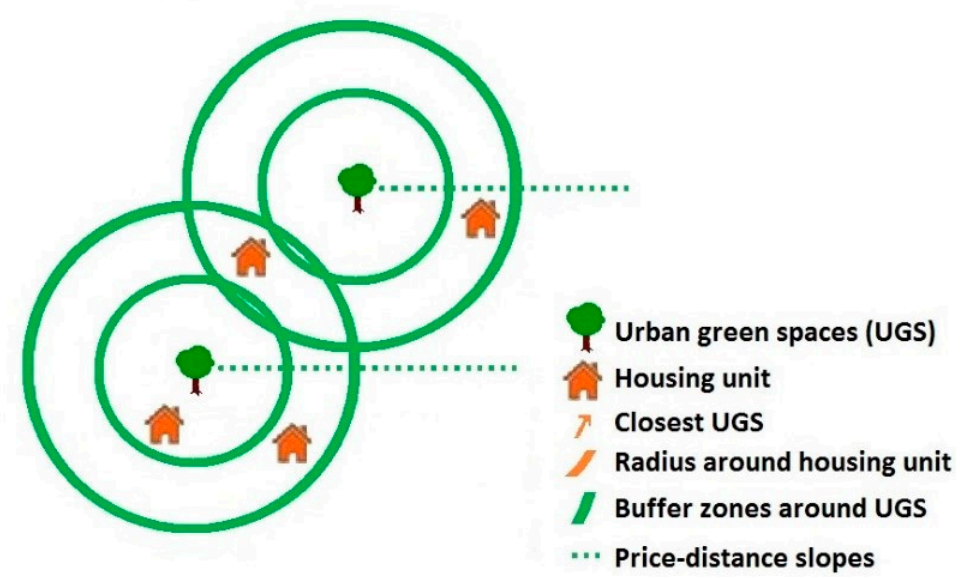

Figure 2. Hedonic pricing analysis (a) and analysis of buffer zones (b).

The alternative approach places UGS in the middle of the analysis. Here, each of the UGS is considered individually; a single housing unit can belong to different buffers around different UGS. Housing units are used to compute mean housing prices at different distances to the UGS. In contrast, housing units are the starting point for hedonic studies (Figure 2a), and the same UGS can be associated with several housing units at once.

To summarize, the proposed approach shifts the starting point from the social-economic or property market sphere of the hedonic pricing analysis into the ecological sphere. We believe that this approach could be an inspiring next step to stimulate the dialogue between scholars from different disciplines about the impacts of UGS onto housing prices.

\subsection{Aims and Organization of the Study}

To test the usefulness of such an analysis of buffer zones around UGS, we take a first step in applying this method to the city of Leipzig, Germany. The objective is to start a scientific discussion about the proposed approach that, in turn, will lead to its further development. To do so, we search for empirical evidence of price-distance slopes around UGS and test whether size as an exemplary UGS characteristic, as well as neighboring UGS, influence these price-distance slopes. 
Therefore, we investigate the following hypotheses:

- H1: there are price-distance slopes around UGS.

We expect to find price-distance slopes around UGS.

- H2: differences in price-distance slopes are related to differences in UGS size.

We expect that price-distance slopes around large UGS are more pronounced since prices around small UGS are potentially influenced also by larger UGS close by (Figure 1).

- H3: neighboring UGS influence price-distance slopes.

We test if the effects of UGS on prices superimpose each other, implying that other UGS in the vicinity influence their effect on prices in their own buffers.

This study builds on the lines of Liebelt et al. [11,23], which analyzed the influence of UGS on housing prices in Leipzig on the city and district scales by using a classical hedonic pricing setting. These studies have found that UGS characteristics (e.g., UGS size) affect housing prices. Notably, these effects differed when analyzed on a city or district level, indicating that spatial heterogeneity requires additional sensible investigation. The partly counter-intuitive results of the previous analysis [15] motivated us to explore the analysis of buffer zones around UGS as a tool to deepen our understanding of the impact of UGS characteristics on housing prices.

In Section 2, we provide information on data and method related to our case study. Section 3 presents the results. Section 4 discusses the hypotheses and the general concept, study limitations, and suggestions for further research. Section 5 concludes.

\section{Materials and Methods}

\subsection{Case Study}

The study area is the city of Leipzig, Germany, with 29,760 ha and approx. 575,000 inhabitants [34]. Leipzig has many UGS of approximately 4900 ha, compared with the 6300 ha of residential areas (Figures 3 and 4a, Section 2.2 for more details). The city is notable for its UGS that are easily accessible and vary in size, with some large parks located not far from the city center and forests located within the city boundary.

Leipzig is a city where renting is more common than purchasing housing units due to several reasons. First, social housing introduced after World War II which made renting of housing units less expensive than purchasing [35]. Second, homeowners in Germany, in contrast to other European countries like the Netherlands or Spain, benefit from subsidies to a lesser extent [35]. Finally, rental prices in Germany have remained relatively stable over a long period of time [35]. During the last few years, however, rental and sales price started to increase, reflecting urbanization and segregation in Germany, in general, and in Leipzig, in particular [36].

In total, residential housing consists of multi-family houses (88\%) and detached and semi-detached houses (12\%). One third of the housing stock was constructed during the Wilhelminian period (i.e., Gründerzeit until 1918), around 19\% of housing units were built between 1919 and 1948, 29\% of houses were built in GDR period between 1960 and 1990 (these are mostly high-rise buildings with 4-12 stories [37]); and 19\% of modern housing units built in post GDR period (i.e., after 1990) [38]. 


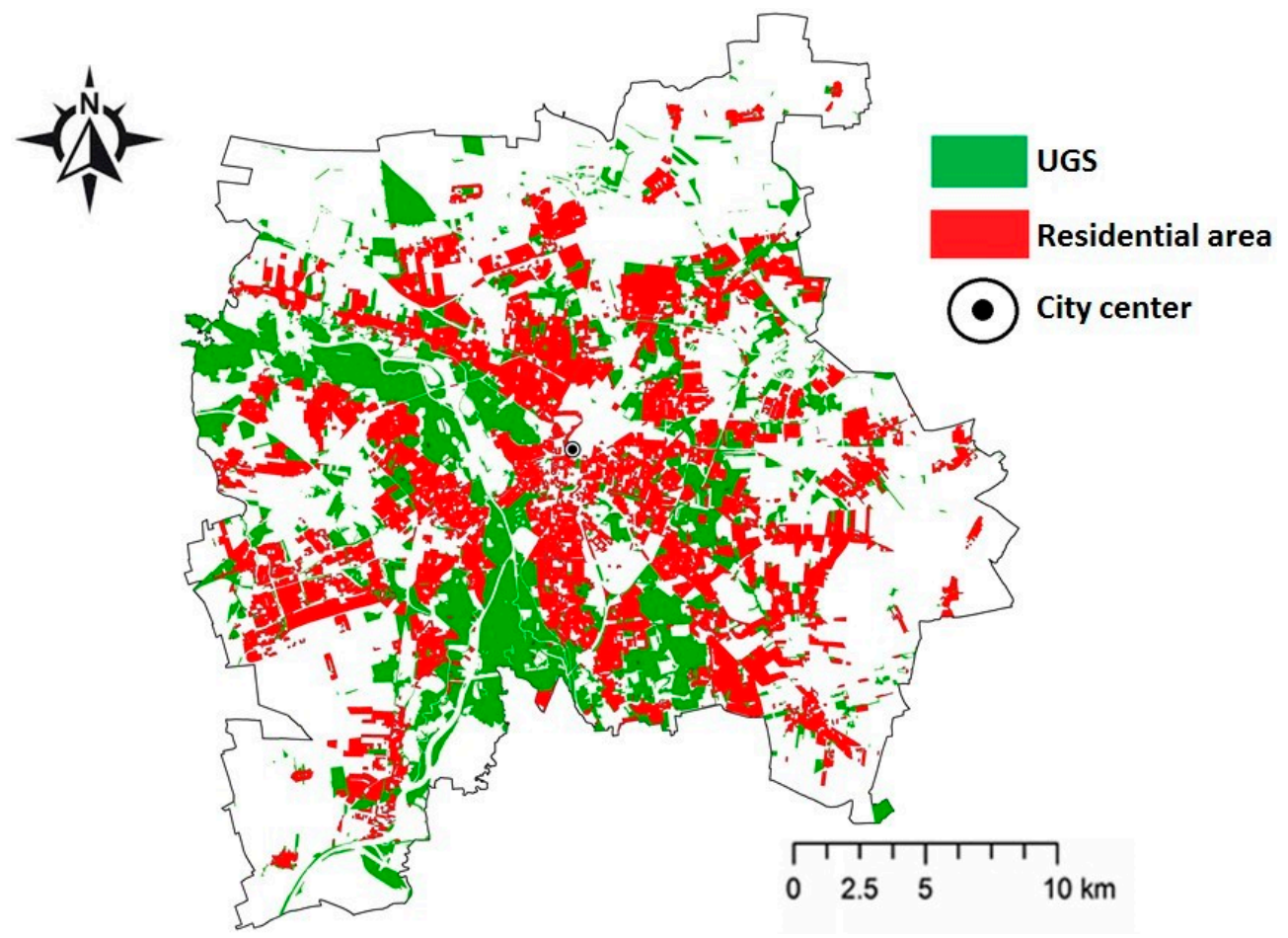

Figure 3. City of Leipzig—composition of urban green spaces (UGS) vs. residential area.

\subsection{Real Estate and Spatial Data}

This study focusses on flats available to rent since, first of all, renting is the most common type of housing; and, second, it was the largest group of housing for which data was available. The real estate data comprises 261,827 flats available for rent in Leipzig for the period of 2007-2013, obtained from the German real estate web portal Immobilienscout24. We carefully examined the data to avoid inconsistencies and exclude unrealistic outliers by applying cut-off criteria: the minimum size for flats was set to $15 \mathrm{~m}^{2}$ and the maximum to $300 \mathrm{~m}^{2}$. Additional corrections related to handling of missing data include logical recoding and imputation (described in detail in Liebelt et al. [11,23]). We obtained spatial data on UGS from Germany's nationally standardized official topographic-cartographic information system for the year 2010 with a spatial resolution of 1:25,000. We combined various UGS types, namely, allotments, forests, cemeteries, and parks, into a single category. We assume that these provide ecosystem services to local residents in a similar extent and are the most suitable to test our hypotheses. However, in order to prove that our previous statement is meaningful, we also analyzed UGS types separately. In total, 744 UGS were included in the analysis, with an average size of 6.9 ha (ranging from $4 \mathrm{~m}^{2}$ to $495.5 \mathrm{ha}$ ). We did not restrict the size of UGS to maintain all raw data and explore the influence of all sizes of UGS.

\subsection{Analysis of Buffer Zones around UGS}

\subsubsection{Data Preparation}

In total, 744 UGS were characterized regarding their distance to the city center (CBD), UGS size (in ha), and UGS share (\%) of other UGS around each UGS in a 2000 m radius. Spatial data analysis and preparation of the study variables were performed in ArcGIS v.10.5. All statistics were calculated using R v. 3.4.0 software [39].

For the price-distance slopes (Section 2.3.2), we calculated the mean rental price per $\mathrm{m}^{2}$ in 20 buffers around each UGS. We created buffers of $100 \mathrm{~m}$ each, because this buffer size has been commonly used in landscape ecology [40-42]; additionally, we found a sufficient number of flats per buffer with this buffer size. Housing units within a specific buffer were used to calculate average rental 
prices per $\mathrm{m}^{2}$. Thus, for each of the UGS, all flats within 20 buffers, that is, up to a distance of 2000 $\mathrm{m}$, were considered (Figure 4). This distance was chosen to capture the price effects of large UGS also. UGS without a large-scale effect on prices result in nonsignificant or nonlinear price-distance slopes (Section 3.1). In the analysis of buffer zones, flats can belong to several buffers of various UGS simultaneously, whereas no double-counting of UGS occurs.

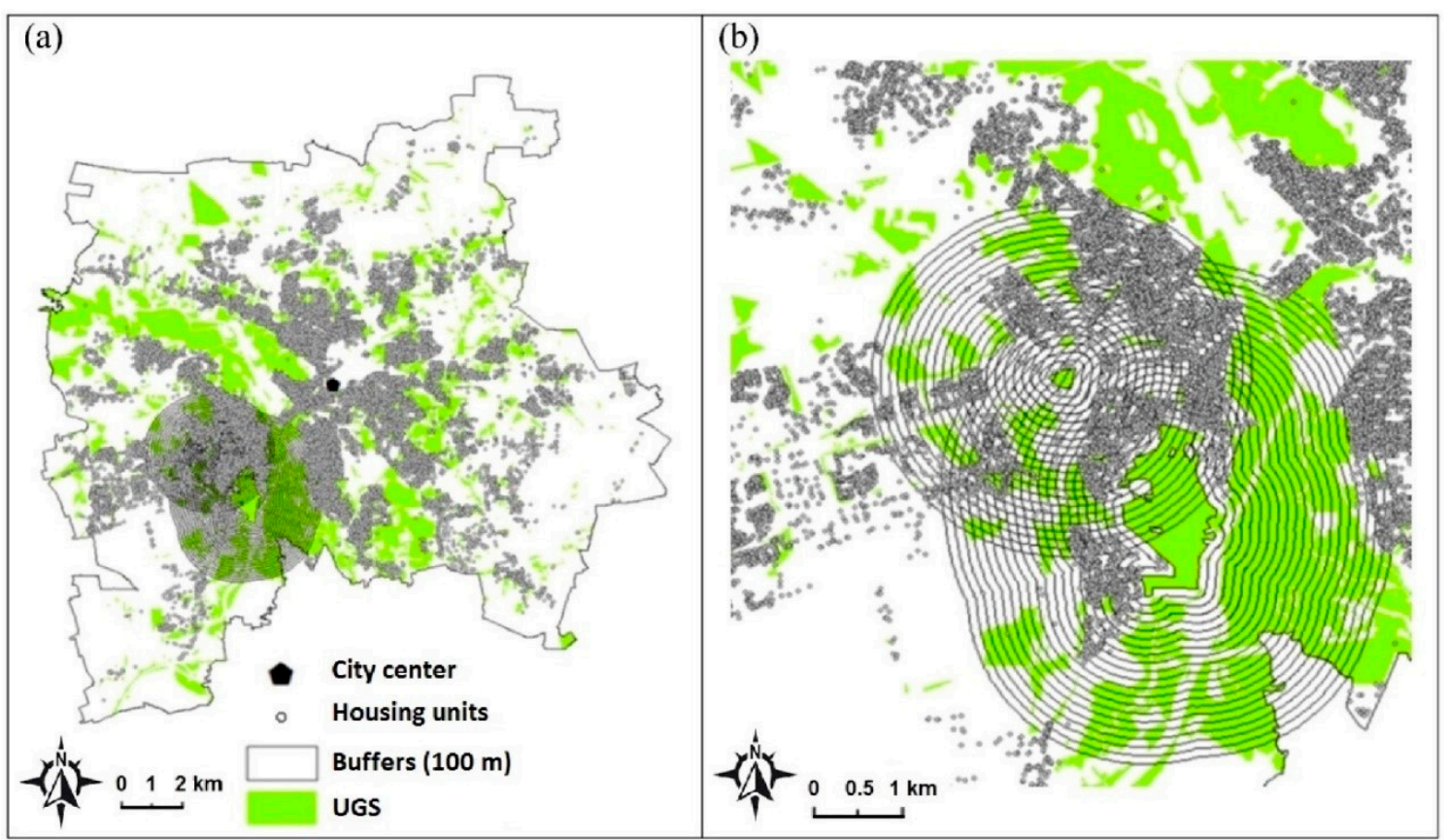

Figure 4. Analysis of buffer zones around UGS with two exemplary UGS *. * same method performed for all 744 UGS; (a) UGS and housing units of Leipzig, and 20 buffers around two randomly selected UGS; (b) a cropped version of (a), presenting buffers around the two UGS in greater detail.

Table 1 lists all the variables considered in the analysis. Mean price is a dependent variable representing the mean rental price for flats located in a particular buffer (from 1 to 20). As a basis for calculation, we used monthly listing flat prices (i.e., requested renting prices stated on the web by the offering party). UGS size was calculated for each of the 744 UGS in hectares. CBD distance was calculated in meters for each of the UGS, with the central train station used as the city center. Additional details on UGS types are presented in Section 2.2.

Table 1. Variables used in the analysis of buffer zones for 744 UGS.

\begin{tabular}{|c|c|}
\hline Variable and Units & Description \\
\hline Mean price $\left(\right.$ Euro $\left./ \mathrm{m}^{2}\right)$ in buffers from $100 \mathrm{~m}$ to $2000 \mathrm{~m}$ & $\begin{array}{l}\text { Mean rental price for all flats located in a buffer, } \\
\text { calculated for } 20 \text { buffers of } 100 \mathrm{~m} \text { radius each. }\end{array}$ \\
\hline UGS Size (ha) & Size of UGS (ha). \\
\hline CBD Distance (m) & Distance from central business district (CBD) to UGS. \\
\hline UGS Share (\%) & $\begin{array}{c}\text { Share (in \%) of UGS in the buffer area of } 2000 \mathrm{~m} \\
\text { around the UGS. }\end{array}$ \\
\hline UGS Types & Types of UGS: allotment, forest, cemetery or park. \\
\hline
\end{tabular}

\subsubsection{Determining Price-Distance Slopes}

Price-distance slopes indicate whether an increase or decrease in rental prices occur with increasing distance to UGS (i.e., while 'moving' from buffer 1 to 20). The visual inspection of changes in price over distance to UGS also indicated nonlinear relationships. Therefore, we applied a Box-Cox 
transformation [43] to identify other appropriate functional forms [44]. The Box-Cox transformation procedures [45] for all UGS indicated that the following values of the coefficient $\lambda$ occur most often: $\lambda=0, \lambda=1, \lambda=-1, \lambda=-2, \lambda=-3$, leading to the transformations presented in Table 2 [46]. Thus, for each UGS, five linear regressions were fitted with transformed mean flat price per $\mathrm{m}^{2}$ per buffer as a dependent variable and buffers (buffer 1 to buffer 20) as independent variable. As the main focus of this study is the change in prices rather than absolute values, we focused on the resulting slopes only and considered slopes significant at the $95 \%$ level.

Table 2. Transformations of mean price per buffer before quantifying price-distance slopes.

\begin{tabular}{ccc}
\hline$\lambda$ & Required Transformation & Explanation \\
\hline 1 & None & Price \\
0 & Natural log & $\log ($ price $)$ \\
-1 & Reciprocal, i.e., power of -1 & $1 /$ price \\
-2 & Power of -2 & $1 /($ price 2$)$ \\
-3 & Power of -3 & $1 /($ price 3$)$ \\
\hline
\end{tabular}

\subsubsection{Hypotheses Testing}

Appendix A summarizes our analysis from data preparation to hypothesis testing. First, we test whether there are price-distance slopes around UGS (H1). Second, we ran linear regressions to analyze the relationships of UGS size and UGS share with price-distance slopes. To account for data skewness (e.g., Appendix E, Appendix F, Appendix G) and outliers [47], we also applied log and square root transformations of UGS size and UGS share [48].

We expect to observe relatively low values of adjusted $R^{2}$ as an outcome of the analysis. Our reasoning was that we explained mean rental prices at different distances to UGS only with UGS size and UGS share. Housing variables (e.g., size and presence of a balcony), which play an important role in explaining prices $[7,15,49,50]$ were not considered because we focused explicitly on UGS in order to test whether we find any empirical evidence for price-distance slopes around UGS.

\section{Results}

This section reports the results for the empirical case study, first explaining the general results on common patterns for UGS that were included and not included in the analysis (Hypothesis 1). Subsequently, the results are provided for analysis of UGS included in the models to test Hypotheses 2 and 3 .

\subsection{Hypothesis 1}

Figure 5; Figure 6 present the amalgam of price-distance slopes for UGS for the city of Leipzig based on average mean price-distance slopes across all UGS. The average price tends to decrease as the distance from the UGS increases. All three potential patterns for the gradients of mean prices $\left(\right.$ Euro/ $\mathrm{m}^{2}$ ) along the buffers of UGS were present. We observed increasing (Figure 5a) and decreasing prices (Figure $5 b$ ) as well as no clear pattern (Figure 5c) when moving from one of the UGS' nearest buffers to those farther away.

The data also indicated that for some UGS, flats are present either in very few buffers or not at all. Hence, we excluded 37 UGS from further analysis (i.e., cases when flats were present in less than four buffers) as the analysis of buffer zones cannot be meaningful in such cases. 


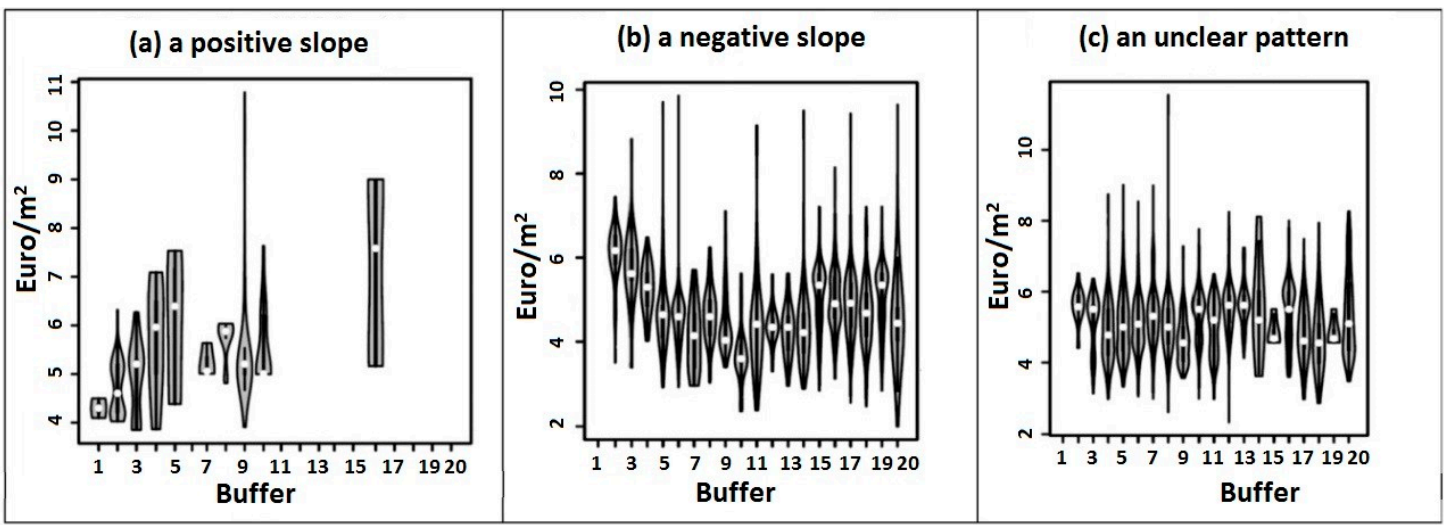

Figure 5. Price-distance slopes examples for 20 buffers around UGS with positive slope (a), negative slope (b), and unclear pattern (c).

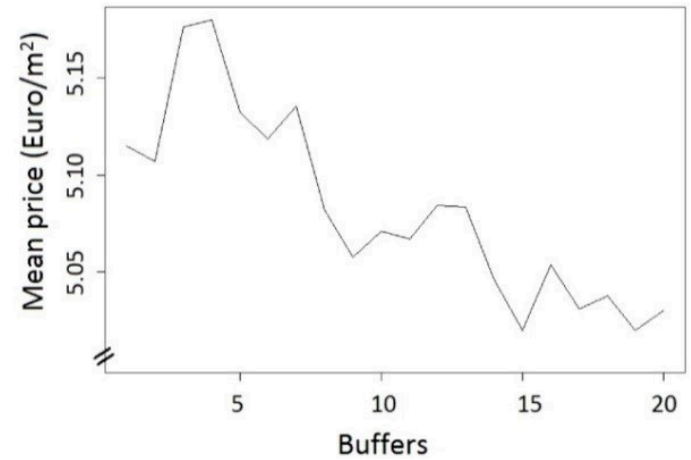

Figure 6. Price gradients across all UGS in Leipzig* * Distribution of mean (untransformed) prices per buffer.

When fitting the price-distance slopes by applying the various price transformations (as indicated in Table 2), 389 UGS were not included in any of the five regression models that relate distance to UGS with a price (Section 2.3.2) at the 95\% significance level. As a result, 355 UGS were included in one or more regression models. Appendix B provides details on how many price-distance slopes were statistically significant for each of the price transformations. Overall, we found some empirical evidence on Hypothesis 1 that price-distance slopes around UGS exist; and, therefore, it was accepted.

We also applied a $t$-test to determine which variables might be related to the fact whether price-distance slopes are significant or not. Figure 7a,b illustrates that CBD distance $(p<0.001)$ and UGS share in $2000 \mathrm{~m}$ buffer $(p<0.0001)$ are clear indicators, whereas UGS size (Figure 7c) is not. In other words, we observe a greater number of significant price-distance slopes for UGS located closer to the CBD and in areas with a higher UGS density in the $2000 \mathrm{~m}$ buffer.
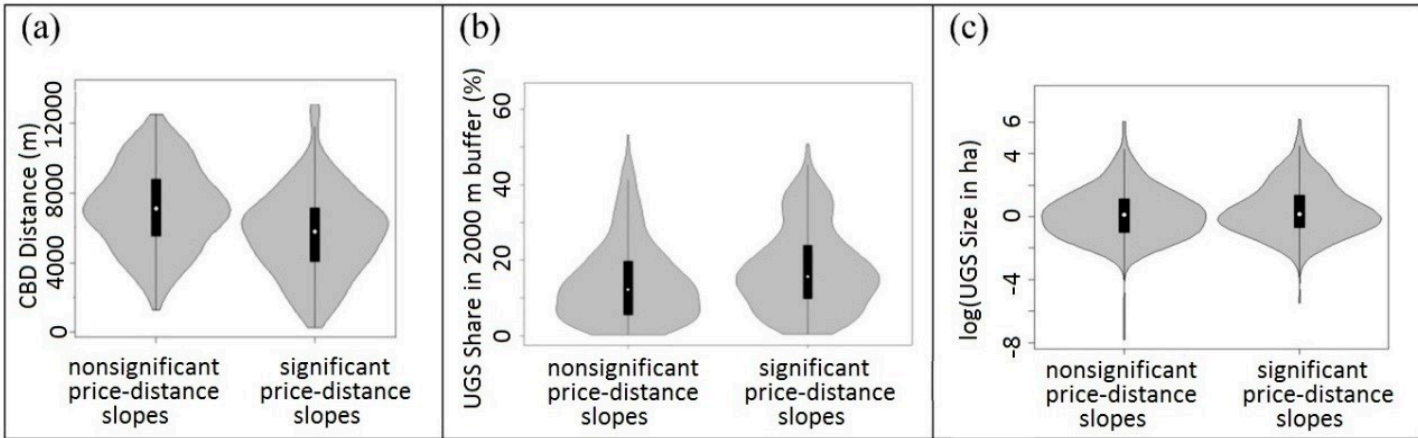

Figure 7. Comparison of significant vs. nonsignificant price-distance slopes for CBD distance (a), UGS share in $2000 \mathrm{~m}$ buffer (b), and UGS size (c). 
We also tested whether price-distance slopes are different for different UGS types. Appendix C summarizes the results of the linear regressions performed to test the relationship between UGS type and the price-distance slopes. None were statistically significant. Additionally, graphical inspection does not hint at any relationship (Appendix D).

\subsection{Hypothesis 2}

To test Hypothesis 2, we ran a $t$-test for positive and negative price-distance slopes and UGS size. The $t$-tests were significant (95\% confidence interval) for logarithmically transformed UGS sizes and logarithmically transformed price-distance slopes (Figure 8, examples of nonsignificant relationships are in Appendix E, scatterplots for UGS size and price-distance slopes are in Appendix F). Results indicated that negative price-distance slopes are more likely to be observed for UGS of smaller size than positive price-distance slopes.

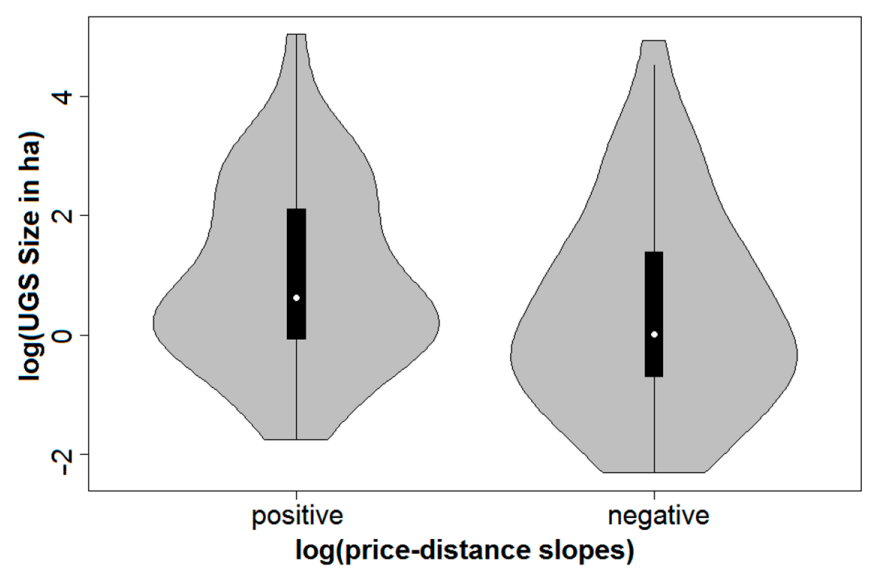

Figure 8. Comparison of positive vs. negative price-distance slopes for different UGS size. Variables underwent logarithmic transformations to account for data skewness and outliers.

The statistical tests described above demonstrate some empirical evidence for the acceptance of H2: differences in price-distance slopes are related to differences in UGS size.

\subsection{Hypothesis 3}

To test Hypothesis 3, we plotted UGS share in a buffer of $2000 \mathrm{~m}$ around each UGS against price-distance slopes (Appendix G) and performed statistical tests (Table 3).

Table 3. Regression results to test if UGS share influences price-distance slopes.

\begin{tabular}{|c|c|c|c|c|c|}
\hline $\begin{array}{c}\text { Transformation of } \\
\text { Price-Distance } \\
\text { Slope }{ }^{1,2}\end{array}$ & $\begin{array}{l}\text { Transformation of } \\
\text { UGS Share in } \\
2000 \text { m Buffer }^{3}\end{array}$ & Intercept & $\begin{array}{l}\text { Estimate for } \\
\text { UGS Share in } \\
2000 \mathrm{~m} \text { Buffer }\end{array}$ & Adj. $R^{2}$ & $p$-Value \\
\hline \multirow{3}{*}{ None } & none & $-0.0006^{*}$ & 0.0002 & 0.001 & 0.270 \\
\hline & $\log$ (UGS share) & $-0.001 *$ & 0.0002 & 0.006 & 0.113 \\
\hline & sqrt(UGS Share) & $-0.0008^{*}$ & 0.0001 & 0.003 & 0.180 \\
\hline \multirow{3}{*}{ Natural log } & None & -0.0003 & 0.00001 & 0.004 & 0.187 \\
\hline & $\log$ (UGS share) & -0.0005 & 0.0002 & 0.008 & 0.121 \\
\hline & sqrt(UGS share) & -0.0005 & 0.0001 & 0.008 & 0.112 \\
\hline \multirow{3}{*}{ Reciprocal } & None & $1.9 \times 10^{-6}$ & $-6.5 \times 10^{-8}$ & 0.001 & 0.274 \\
\hline & $\log$ (UGS share) & $1.7 \times 10^{-6}$ & $-4.0 \times 10^{-7}$ & -0.004 & 0.638 \\
\hline & sqrt(UGS share) & $3.0 \times 10^{-6}$ & $-5.6 \times 10^{-7}$ & 0.002 & 0.254 \\
\hline \multirow{3}{*}{ Power of -2} & None & $3.8 \times 10^{-9}$ & $-2.0 \times 10^{-10}$ & -0.005 & 0.888 \\
\hline & $\log$ (UGS share) & $-8.4 \times 10^{-8}$ & $5.9 \times 10^{-8}$ & 0.0066 & 0.140 \\
\hline & sqrt(UGS share) & $1.9 \times 10^{-9}$ & $1.2 \times 10^{-8}$ & -0.005 & 0.872 \\
\hline
\end{tabular}

${ }^{1}$ See Table 2. ${ }^{2}$ price-distance slopes that sometimes underwent various transformations (see Section 2.3.2)-dependent variable; ${ }^{3}$ UGS share in 2000 buffer that sometimes underwent various transformations to account for data skewness and outliers (see Section 2.3.3)—as independent variable. 
We observed no statistically significant relationship $(p>0.001)$ between neighboring UGS and the price-distance slopes (Table 3). Thus, H3: neighboring UGS influence price-distance slopes, was rejected.

\section{Discussion}

\subsection{Hypothesis 1}

The analysis of buffer zones around UGS applied in this study provides additional details on the price-distance slopes with regard to the variable UGS distance that has been very often analyzed in hedonic studies [7,13,49-52]. In the majority of hedonic studies, UGS distance demonstrated negative effects on real estate prices [49,52,53], that is, the shorter the distance to UGS, the higher the housing price. Notably, an opposite effect of UGS distance on prices was found for the Leipzig case study [15].

The analysis undertaken in Section 3 leads to the acceptance of Hypothesis 1. There are two meaningful outcomes in respect to Hypothesis 1 that are worth mentioning. Firstly, about half of the UGS have significant price-distance slopes, regardless of the housing characteristics influencing prices. Secondly, there is a huge diversity (positive and negative slopes, different transformations possible) that needs more work in the future.

Moreover, our analysis did not find different price-distance slopes for different UGS types such as allotments, forests, cemeteries or parks. For hedonic studies, some authors have argued that analyzing various types of UGS separately, instead of a single aggregated UGS variable (that combines various UGS types), might provide more detailed and precise results [54]. Other authors have argued it is not always feasible due to a large number of variables [15]. The fact that we did not find any evidence of different price-distance slopes depending on UGS types indicates that our decision to aggregate the types of UGS did not lead to a substantial loss of information in this case study.

\subsection{Hypothesis 2}

Before discussing the results for Hypothesis 2, assessing the magnitude of the effects is worthwhile. The analysis demonstrated very low values of explanation of variable variances (adjusted $R^{2}$ ). This result should not lead to the misjudgment that these outcomes are not worthy of further discussion. Moreover, our intention (Section 2.3.3) was not to explain the variance of prices as best as possible but to provide additional details on UGS and test whether we would observe significant linear models and the direction of effects. Overall, the results support Hypothesis 2: differences in price-distance slopes are related to differences in UGS. This hypothesis covers the interaction of two attributes commonly analyzed in hedonic studies: UGS size and distance to UGS.

For UGS size, hedonic studies have found a positive effect on housing prices [15,55], arguing that larger UGS offer additional recreational opportunities and greater access to flora and fauna in contrast to smaller UGS [56]. A negative impact of UGS distance on prices is commonly assumed and has been found in hedonic studies [34,37], implying that prices decrease with increasing distance to UGS. Notably, for the case study Leipzig, we have found that UGS distance had a positive influence on the flats' sale prices (i.e., that housing prices increase with increasing distance to UGS) [15].

The results of these buffer zones focused study allowed investigating the interaction between the two variables-UGS size and distance to UGS. Environmental interest groups and urban planners can use the results of such regression analysis to show that UGS size has a positive impact (i.e., positive regression coefficient) on price-distance slopes, that is, rental price increases with increasing distance to UGS (i.e., positive price-distance slopes) for UGS of bigger size. The opposite phenomenon applies for smaller UGS: mean prices decrease with increasing distance to UGS.

The results should be interpreted with caution: The common assumption-that decreasing distance to UGS causes an increase in real estate prices-holds for UGS of smaller sizes. Thus, we are tempted to assert: If UGS are within a short walk, they are likely to cause an increase of real estate values-for all the often-stated reasons (e.g., scenic view, microclimate effects and areas for 
recreation). For larger UGS, the situation is different and considerably more difficult to interpret. Assuming our result is not unique for the specific case study Leipzig, we conclude that large UGS (greater than or equal to $100 \mathrm{ha}$ ) might be regarded by inhabitants as a characteristic element of their neighborhood and a unit with specific land uses and attributes comparable to a sports stadium or amusement park. These facilities are connoted with offering services but can also carry disservices to nearby residential inhabitants, for example, due to incoming and outgoing traffic from the respective locations. Additionally, we found out that a number of other factors have an impact on housing prices in relation with UGS size at the district level. For instance, an increase in population density causes an increase of the UGS size coefficient [57]. In other words, urban residents are willing to pay higher prices for housing units located next to UGS of small sizes in a case when population density is low and vice versa. One of the potential explanations here is that the competition for a public good is rather low (i.e., small UGS) when there is a low population density. What is more, Leipzig has an outstanding abundance of UGS and it is well known that it is a scarcity that makes things more valuable. These aspects might partly explain the negative influence of decreasing distance on prices for large UGS.

The findings presented in Section 3.2 indicate that the relationship between the UGS-related variables and prices is complex. This result is in line with the literature that indicated that the impact of UGS-related variables in general, as well as UGS size and UGS distance in particular, are scale-dependent and have different directions regarding the effects on the district level, in contrast to the city level [57].

To summarize, we found that with increasing UGS size, the impact of UGS distance on rental prices changes from negative to positive. Therefore, we recommend considering the interaction of UGS distance and UGS size within the hedonic pricing models, for example, by creating a variable $\ln$ (size/distance) as suggested by Kong et.al [7]. Additionally, this type of analysis improves the understanding of the roles of large and small UGS.

\subsection{Hypothesis 3}

Our analysis calls for the rejection of Hypothesis 3: neighboring UGS influence price-distance slopes.

It is critical to not confuse the variable mentioned in this hypothesis (i.e., neighboring UGS) with the variable used in hedonic analysis (i.e., share of UGS in a particular radius around the housing unit) as UGS share represents the 'greenness' of the area and can demonstrate a statistically significant impact on prices $[10,15]$. In case of analysis of buffer zones, with UGS being in the center of the analysis, the presence of other UGS in the surroundings of the analyzed UGS could have blurred the effect that the single UGS has on price-distance slopes.

\subsection{Limitations of the Study}

This study has several limitations concerning data availability. First, due to the lack of data on private gardens, we could not assess their influence on the price-distance slopes.

Second, as the real estate data in this study depended exclusively on user entries on the real estate website, it did not have high overall reliability, for example, due to missing values. Nevertheless, there is no reason to assume that any systematic error occurred and biased the results. For a discussion on the specific limitation regarding the real estate data, please refer to Liebelt et al. [11].

Third, this study used flats available for rent to apply the analysis of buffer zones around UGS. This factor limited our ability to relate our outcomes to hedonic studies in the literature, in which the majority have analyzed housing units for sale. However, the purchasing of a housing unit is a form of real estate transaction that is far less common in Germany; thus, the insufficient data would have prevented a proper analysis.

\subsection{Suggestions for Future Research}

With our study, we took the first step towards an analysis of buffer zones around UGS in respect with housing prices. We explored available data for one empirical case study and found that-not 
accounting for housing characteristics-we were able to identify price-distance slopes around UGS which are dependent on UGS size. We suggest two ways for the potential further development of the proposed approach. Both would account for the variety of factors that are usually considered in hedonic pricing studies (e.g., proximity to bus stops, schools, city center) and omitted our data exploration. The first option would be to run a classical hedonic analysis with housing units at the center of analysis and afterwards analyze the residuals of the regression function in the analysis of buffer zones. The second (alternative way) would be to include a similar set of independent variables that are commonly used in hedonic pricing analysis into the analysis of buffer zones (i.e., as regression function) by computing, for instance, mean flat size for all buffers. In addition, for obtaining further details or more clarity on the impact of the UGS size on the housing prices we suggest performing an analysis with UGS that were grouped based on the size. Moreover, acknowledging potential spatial autocorrelation, it might be meaningful to apply appropriate regression models e.g., [13,42] and to address endogeneity and discuss an identification strategy.

In our study, we considered distance isotopically, that is, without considering the direction (e.g., south, north, east, or west) when determining the price-distance slopes and calculated the other variables. In this respect, we argue that by considering the mean prices within the buffers, we avoided a potential bias of the results because all potential influences of directions (if any) were levelled out. Nevertheless, investigating potential influences that occur in the different directions of the gradients might provide notable outcomes in similar studies.

Our study made use of the hedonic pricing approach, which is only valid for those ecosystem services immediately perceived and appreciated by residents. A very different perspective from this is the common good perspective asking for the total economic value of the UGS in a city (including future generations). This approach could also be tested and assessed by appropriate economic monetization methods e.g., $[20,21]$.

\section{Conclusions}

This study attempted to analyze the effect of UGS characteristics on housing prices from a different perspective than typically adopted in the hedonic pricing literature. In our explorative analysis of buffer zones, we placed UGS in the center of analysis, in contrast with the classical concept of hedonic studies where housing units are the starting points of all calculations. The objective of the study was to initiate a scientific discussion about the advisability of changing the perspective in the UGS valuation by linking analysis of buffer zones to the hedonic studies. Our study is only the explorative first step and, therefore, further steps should be undertaken in order to enable its efficient and meaningful application.

Our data exploration was guided by three hypotheses on whether price-distance slopes can be found (Hypothesis 1) and whether UGS size (Hypothesis 2) and presence of other UGS (Hypothesis 3) influence these slopes.

In respect with Hypothesis 1 we found empirical evidence on the presence of price-distance slopes around UGS.

Regarding Hypothesis 2, we concluded that UGS size influences price-distance slopes. Thus, this hypothesis was accepted. We found that with increasing UGS size, the impact of UGS distance on rental prices changes from negative to positive, that is, rental prices increase with increasing distance to UGS for the larger UGS and vice versa for the smaller UGS.

For Hypothesis 3, we found no significant influence of neighboring UGS in the radius of $2000 \mathrm{~m}$ on the price-distance slopes.

By flipping the perspective from housing units as the starting point (hedonic pricing analysis) to UGS (analysis of buffer zones), we hope to open the floor for further investigations of the effects of UGS on housing prices with UGS being the center of analysis. Thus, we conclude that analysis of buffer zones can be a meaningful approach for UGS valuation once linked to hedonic pricing. There are several potential advantages associated with application of the proposed approach. Firstly, additional detail about the distance to UGS that cannot be captured with a hedonic pricing analysis can 
be obtained. For instance, in this case study, an increase and decrease of rental prices with increasing distance to UGS are observed. As for the case of Leipzig, we argue that analysis around buffer zones can provide additional information regarding the effect of UGS on prices, in contrast to hedonic studies, where univocal results can be caused by an averaging effect [57]. Secondly, investigating such relations with a clear focus on UGS is possible. In this study, we relate the prices-distance slopes to UGS size and share of UGS in a $2000 \mathrm{~m}$ buffer. Changing this perspective means that many more UGS characteristics could be easily investigated, for instance, the shape of UGS, the specific type of UGS such as forest versus park, or the availability of UGS-related infrastructures such as benches, lights or bins. In the long run, such investigations could support more informed decisions on efficient urban UGS management.

On the whole, with this contribution, we encouraged to change perspective from housing units to urban green spaces becoming the center of analysis. At the moment analysis of buffer zones around UGS, as presented in this study, is only a starting point that obviously requires further investigation and development. Further discussion of the methodological approach will show if and which additional insights it can yield.

Author Contributions: Conceptualization V.L., N.S. and S.B.; methodology, V.L., N.S. and S.B.; investigation, V.L.; data curation V.L. and N.S.; formal analysis V.L.; visualization V.L.; writing-original draft, V.L.; writing—review and editing, V.L, N.S. and S.B.

Funding: This research received no external funding.

Acknowledgments: The authors highly appreciate the support and assistance of those who made this research possible. First of all, we would like to express our sincere gratitude to Robert Holländer at Leipzig University, as our scientific discussions and his constructive comments and suggestions have improved the analysis. We also thank Cheng Guo for his input into the statistical portion associated with the application of $\mathrm{R}$ Software. In addition, we would like to thank Madhumitha Jaganmohan for final language polishing. We are grateful to Immobilien Scout $\mathrm{GmbH}$ for providing real estate data within its transparency campaign. We would like to thank ESCALATE (VH-KO-613), the Department of Computational Landscape Ecology, Working group Biodiversity and Ecosystem services, UFZ, and Graduate school HIGRADE for financial support throughout the PhD project of the first author. None of the sponsors had any influence on the study design or any involvement in the collection, analysis, or interpretation of the data, other than as identified.

Conflicts of Interest: The authors declare no conflict of interest. 


\section{Appendix A}
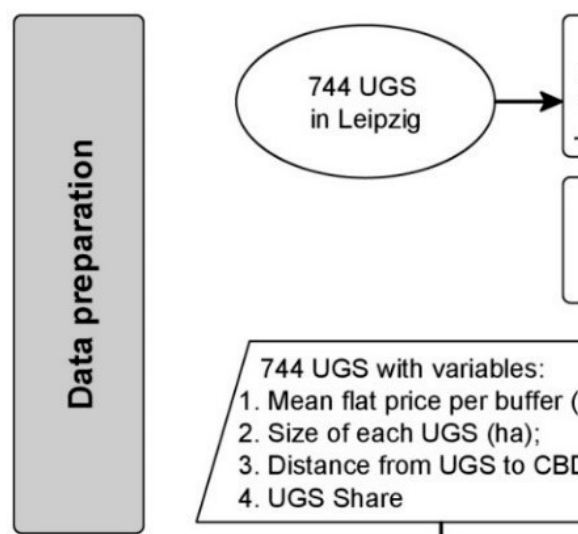
Calculating:
-Distance from CBD
to each UGS (in m);
- Size of UGS (in ha)

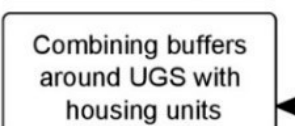

Creation of 20 buffers around each UGS housing units

744 UGS with variables:

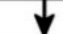

1. Mean flat price per buffer

2. Size of each UGS (ha);

3. Distance from UGS to CBD (m);

4. UGS Share

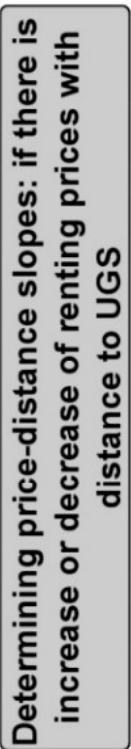

Data screening:

excluding UGS with less than 3 buffers

with data on "Mean price per buffers"
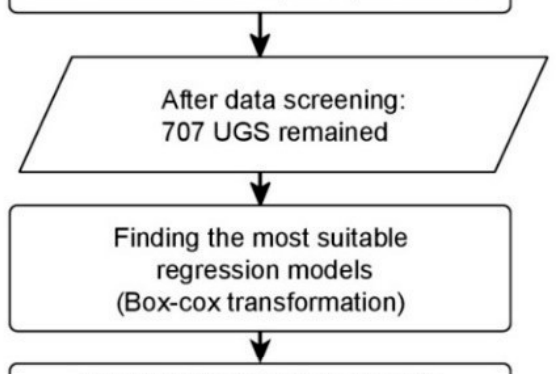

Running 5 regressions models (i.e linear, logistic,

"lambda = -1", "lambda = -2"

"lambda $=-3$ " regressions)

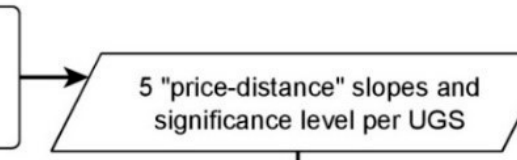

355 UGS covered by at least one regression

Testing of hypotheses on

"Price gradients" (H1); "UGS Size" (H2); and "UGS Share" $(\mathrm{H} 3)$

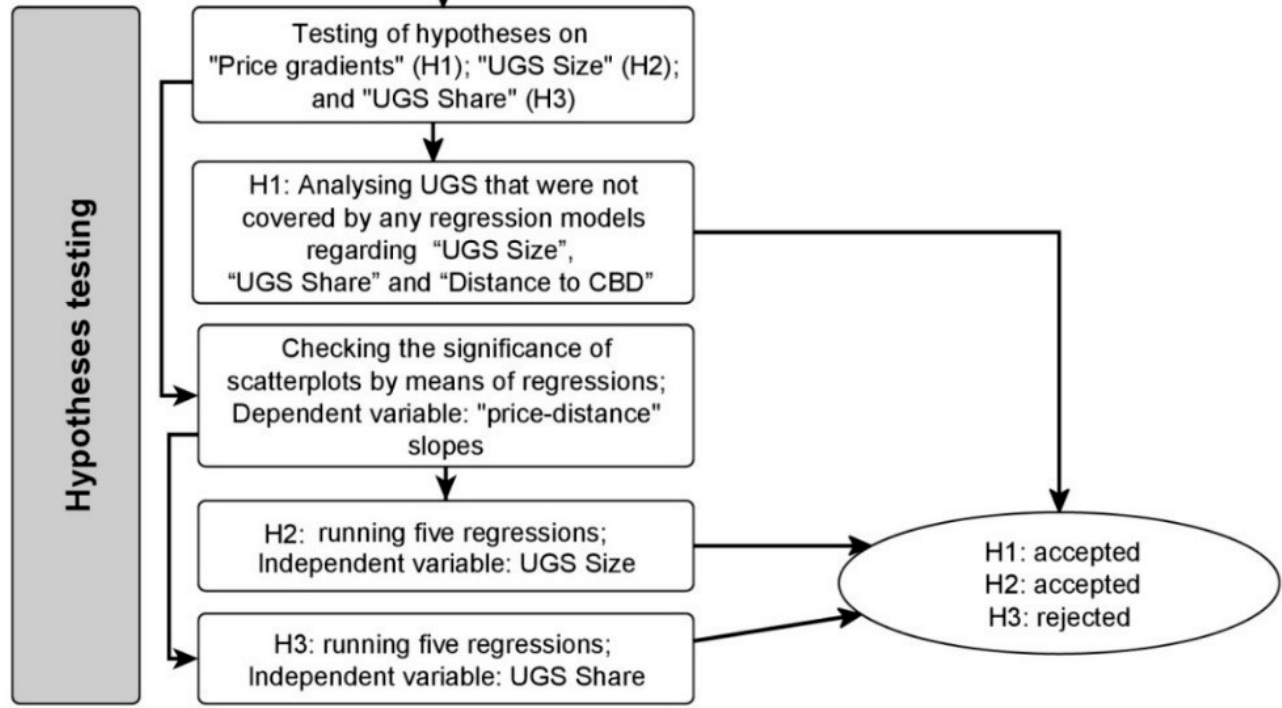

Figure A1. Analysis overview. 


\section{Appendix B}

Table A1. Number of cases for different types of regression. ${ }^{*}$ Cut-off means that those UGS containing flats only in the buffers $0-3$ were excluded (see Section 2.3.2 for more details).

\begin{tabular}{|c|c|}
\hline & Total Number of UGS \\
\hline Total for 20 Buffers & 744 \\
\hline \multicolumn{2}{|c|}{ I. Regression with untransformed prices $($ lambda $=1)$} \\
\hline Significance level of 95\%, all 20 buffers & $245(32 \%$ of total $)$ \\
\hline Significance level of $95 \%$, cut-off* applied & $233(31 \%$ of total $)$ \\
\hline \multicolumn{2}{|c|}{ II. Regression with log-transformed prices (lambda $=0$ ) } \\
\hline Significance level of 95\%, all 20 buffers & $192(26 \%$ of total $)$ \\
\hline Significance level of $95 \%$, cut-off applied & $180(24 \%$ of total $)$ \\
\hline \multicolumn{2}{|c|}{ III. Regression with reciprocal transformation of prices (lambda $=\mathbf{- 1}$ ) } \\
\hline Significance level of 95\%, all 20 buffers & $188(25 \%$ of total $)$ \\
\hline Significance level of $95 \%$, cut-off applied & $176(24 \%$ of total $)$ \\
\hline \multicolumn{2}{|c|}{ IV. Regression with 'power of -2 transformation' of prices (lambda= -2$)$} \\
\hline Significance level of $95 \%$, all 20 buffers & $184(25 \%$ of total $)$ \\
\hline Significance level of $95 \%$, cut-off applied & $172(23 \%$ of total $)$ \\
\hline \multicolumn{2}{|c|}{ V. Regression with 'power of -3 transformation' of prices (lambda $=-3$ ) } \\
\hline Significance level of $95 \%$, all 20 buffers & $190(26 \%$ of total $)$ \\
\hline Significance level of $95 \%$, cut-off applied & $178(24 \%$ of total $)$ \\
\hline
\end{tabular}

\section{Appendix C}

Table A2. Regression results to test Hypothesis $1 .^{\circ}$ See Table 2.

\begin{tabular}{cccccc}
\hline $\begin{array}{c}\text { Transformation of } \\
\text { Price-Distance Slope }\end{array}$ & UGS Type & Intercept & $\begin{array}{c}\text { Estimate for } \\
\text { Selected UGS } \\
\text { Type (Binary) }\end{array}$ & Adj. R2 & $p$ Value \\
\hline \multirow{2}{*}{ None } & Allotment & -0.0005 & 0.0004 & 0.004 & 0.15 \\
& Forest & -0.0002 & -0.0001 & -0.0003 & 0.59 \\
& Cemetery & $-3.5 \times 10^{-4}$ & $-2.2 \times 10^{-6}$ & -0.004 & 0.996 \\
& Park & -0.0004 & 0.0003 & -0.002 & 0.48 \\
\hline \multirow{5}{*}{ Natural log } & Allotment & -0.0002 & 0.0002 & -0.001 & 0.34 \\
& Forest & $1.7 \times 10^{-5}$ & $-1.7 \times 10^{-4}$ & -0.001 & 0.37 \\
& Cemetery & $-1.1 \times 10^{-4}$ & $1.6 \times 10^{-4}$ & -0.004 & 0.59 \\
& Park & $-1.1 \times 10^{-4}$ & $1.2 \times 10^{-4}$ & -0.004 & 0.65 \\
\hline & Allotment & $1.2 \times 10^{-6}$ & $-1.5 \times 10^{-6}$ & 0.001 & 0.26 \\
& Forest & $-1.3 \times 10^{-6}$ & $2.7 \times 10^{-6}$ & 0.014 & 0.06 \\
& Cemetery & $9.8 \times 10^{-7}$ & $-4.3 \times 10^{-6}$ & 0.013 & 0.07 \\
& Park & $6.9 \times 10^{-7}$ & $-8.2 \times 10^{-7}$ & -0.005 & 0.69 \\
\hline
\end{tabular}




\section{Appendix D}

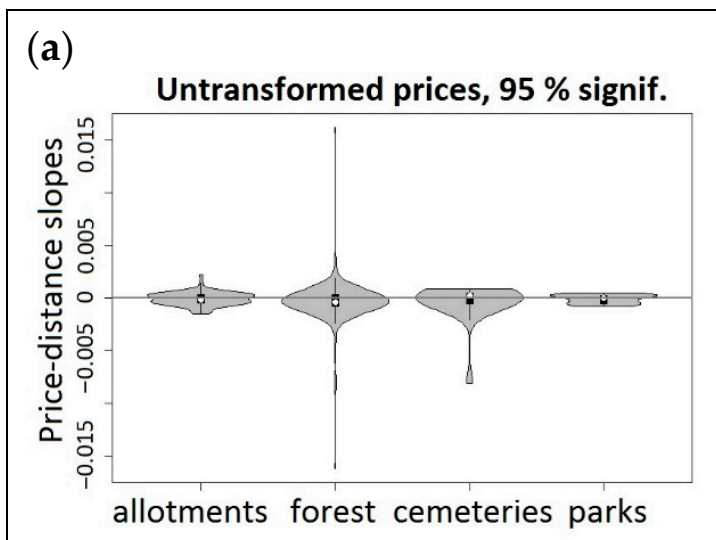

(b)

Log-transformed prices, $95 \%$ signif.

(c)

Reciprocal transformation, $95 \%$ signif.
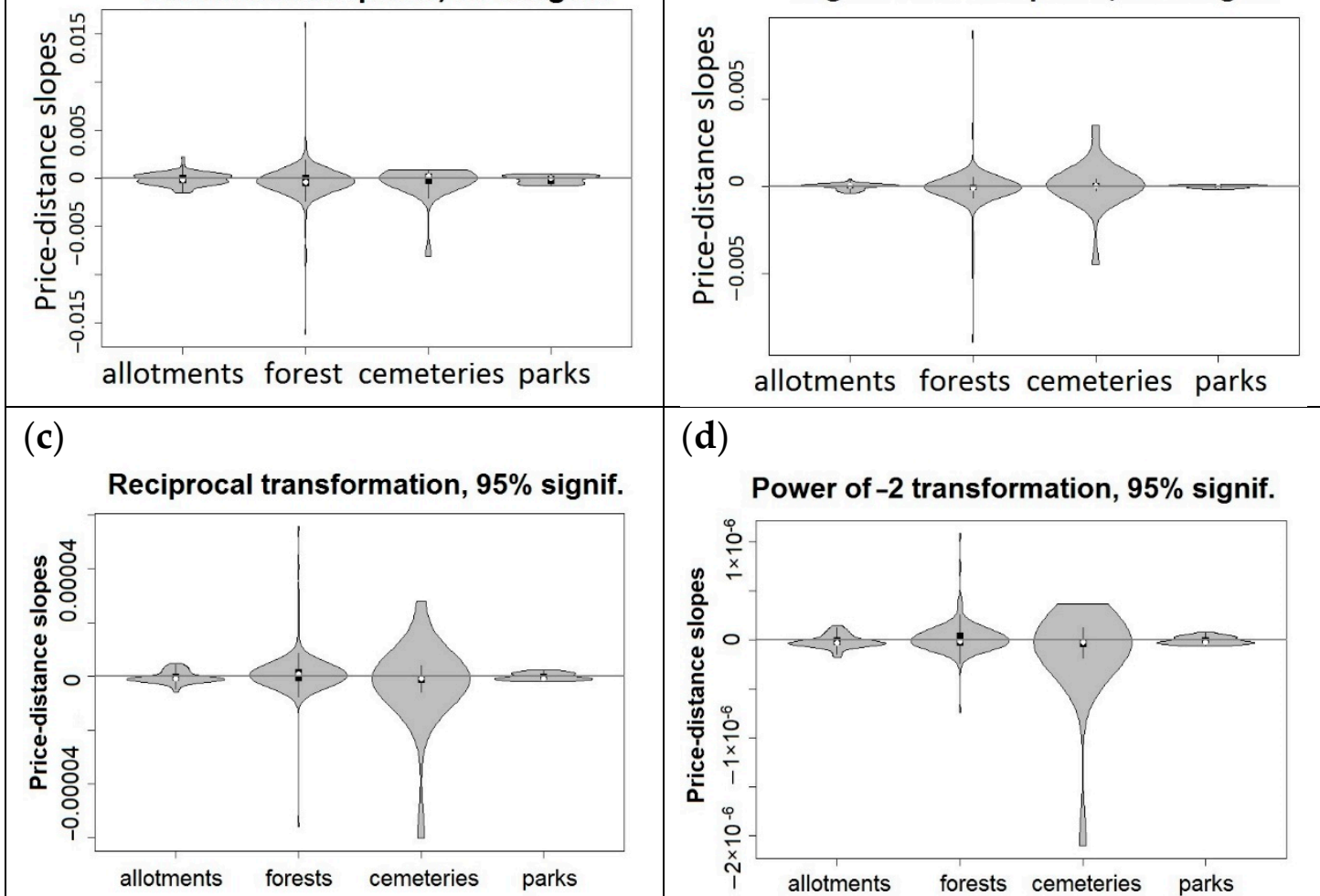

(d)

Power of -2 transformation, $95 \%$ signif.

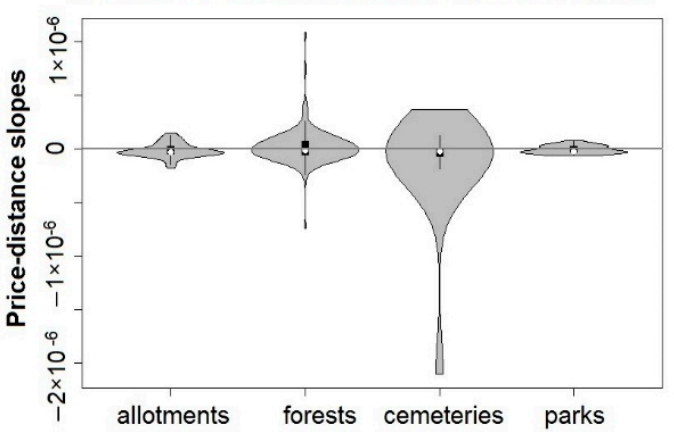

(e) Power of -3 transformation, $95 \%$ signif.

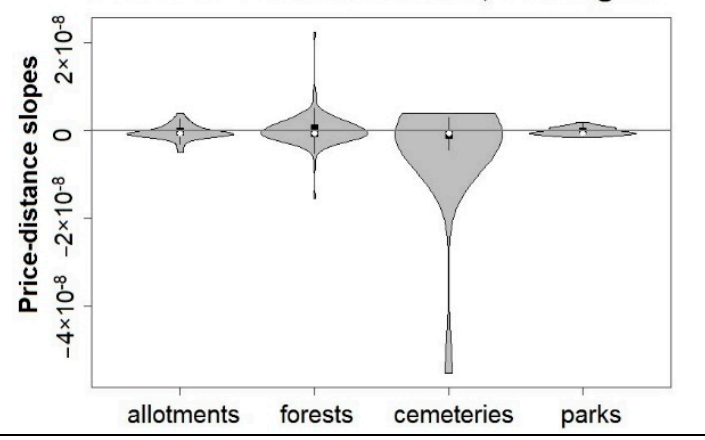

Figure A2. Variation of price-distance slopes for untransformed (a) prices for UGS types and prices with logarithmic transformation (b) and transformations of lambda $=-1(\mathbf{c})$, lambda $=-2(\mathbf{d})$, and lambda $=-3(\mathbf{e})$. 


\section{Appendix E}

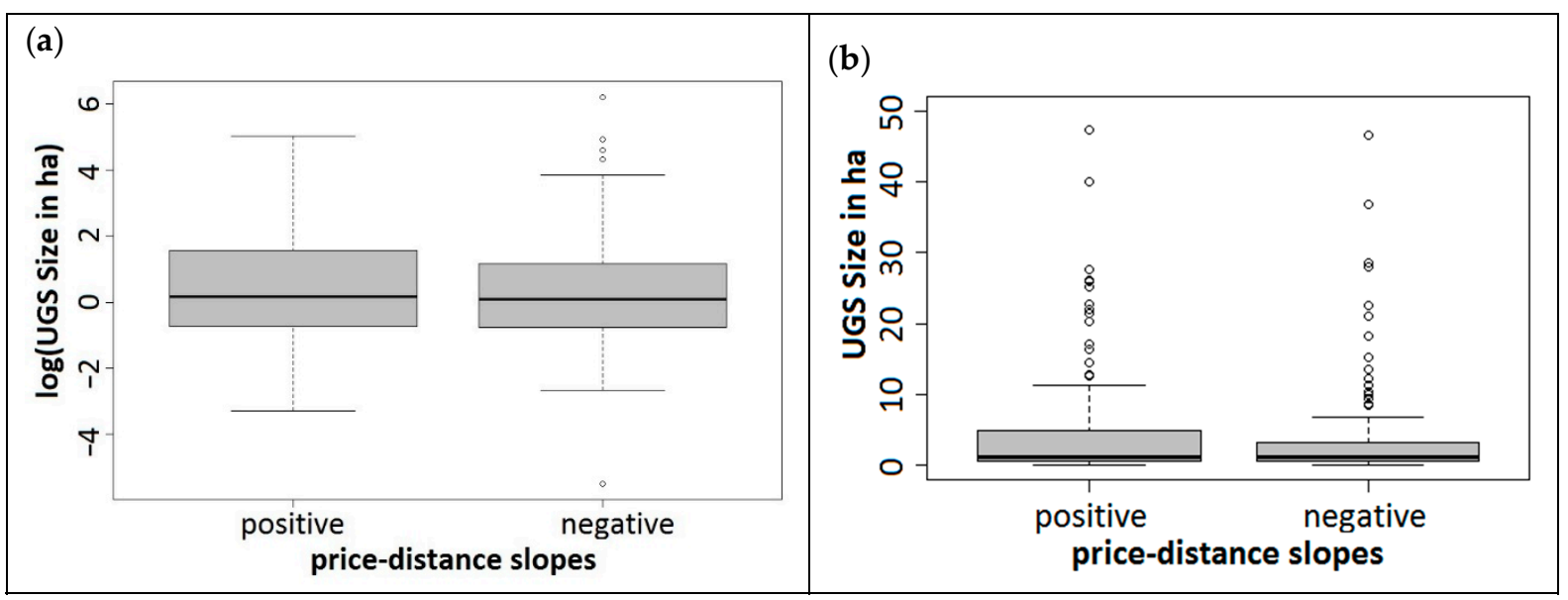

Figure A3. Comparison of positive vs. negative price-distance slopes for different UGS. Some variables underwent logarithmic transformations to account for data skewness and outliers.

\section{Appendix F}

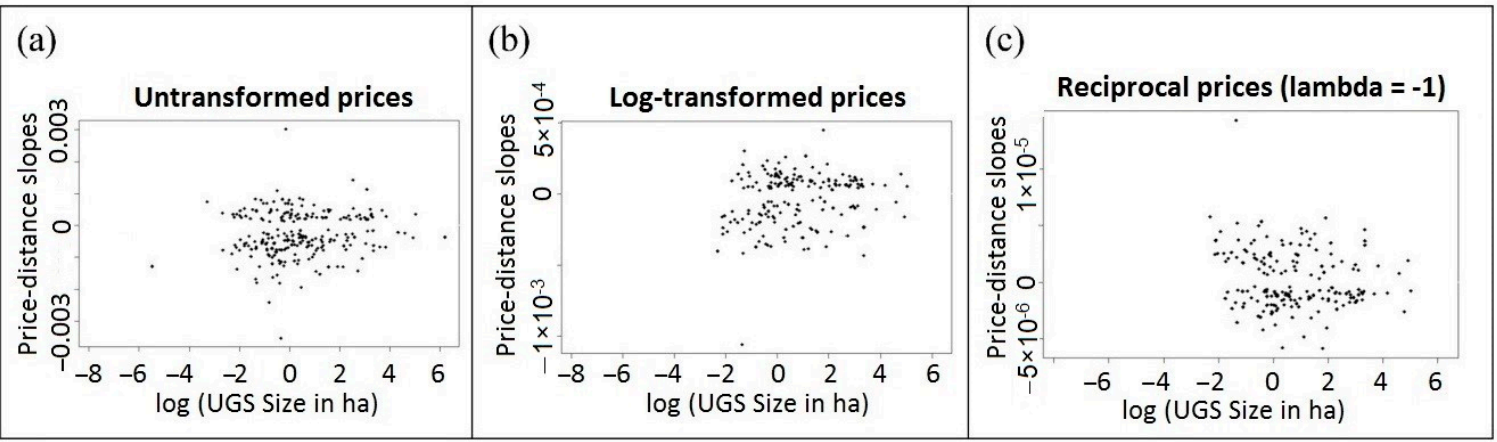

Figure A4. Price-distance slopes in relation to UGS size (ha) presenting statistically significant linear relationships for untransformed prices (a), log-transformation (b), and reciprocal transformation (c) of prices with log (UGS size), 95\% significance level. 


\section{Appendix G}

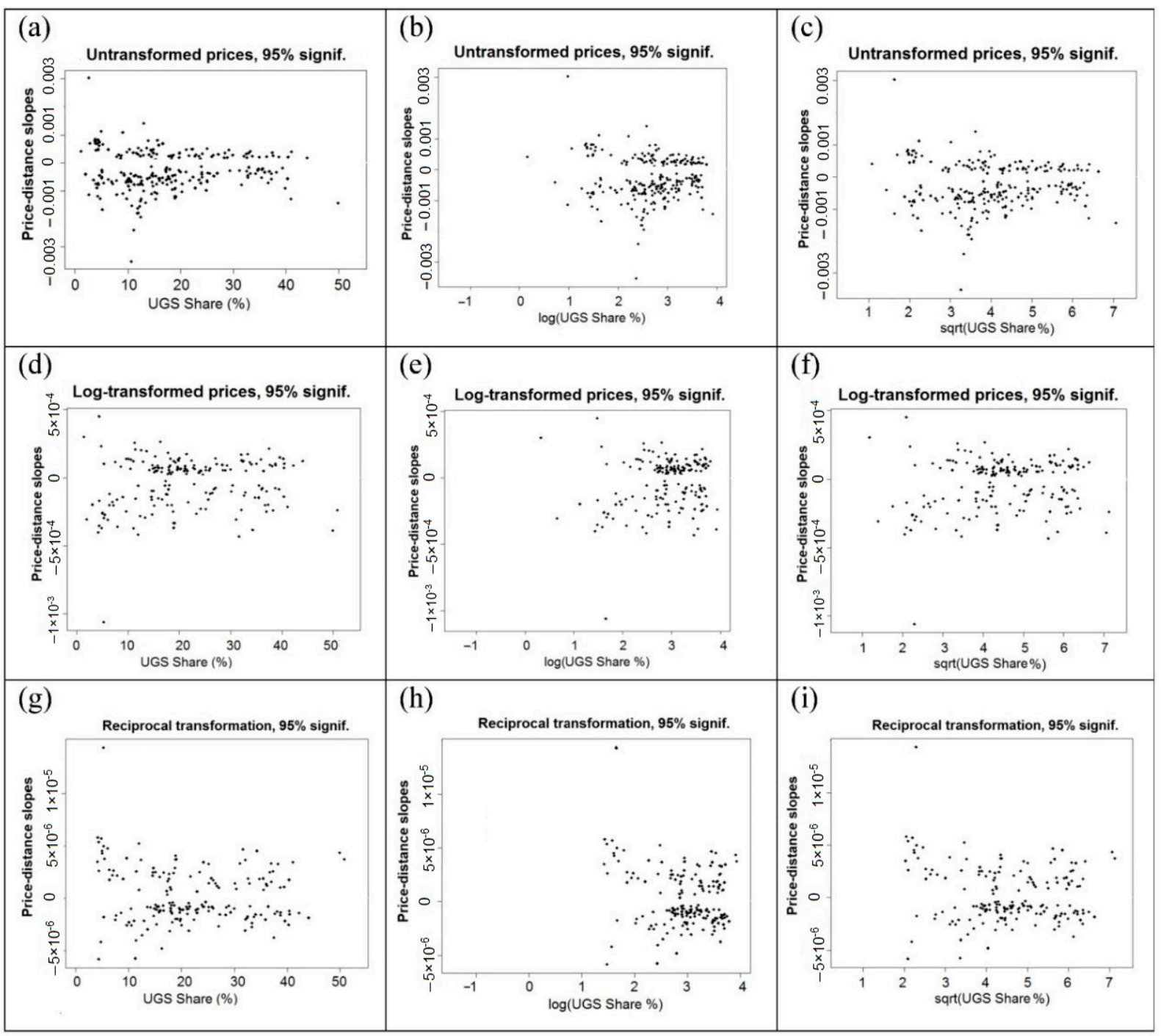

Figure A5. Price-distance slopes in relation to UGS share in $2000 \mathrm{~m}$ buffer (\%).

\section{References}

1. Haase, D.; Larondelle, N.; Andersson, E.; Artmann, M.; Borgström, S.; Breuste, J.; Gomez-Baggethun, E.; Gren, Å.; Hamstead, Z.; Hansen, R.; et al. A Quantitative Review of Urban Ecosystem Service Assessments: Concepts, Models, and Implementation. Ambio 2014, 43, 413-433. [CrossRef] [PubMed]

2. Bolund, P.; Hunhammar, S. Ecosystem services in urban areas. Ecol. Econ. 1999, 29, 293-301. [CrossRef]

3. Millennium Ecosystem Assessment, Ecosystems and Human Well-Being: Biodiversity Synthesis, Washington, DC. 2005. Available online: https://www.millenniumassessment.org/documents/document.354.aspx.pdf (accessed on 20 December 2017).

4. Daily, G.C. Nature's Services. Societal Dependence on Natural Ecosystems; Island Press: Washington, DC, USA, 1997.

5. Costanza, R.; D’Arge, R.; de Groot, R.; Farber, S.; Grasso, M.; Hannon, B.; Limburg, K.; Naeem, S.; O’Neill, R.V.; Paruelo, J.; et al. The value of the world's ecosystem services and natural capital. Nature 1997, 387, 253-260. [CrossRef]

6. Rosen, S. Hedonic prices and implicit markets: Product differentiation in pure competition. J. Political Econ. 1974, 82, 34-55. [CrossRef]

7. Morancho, A.B. A hedonic valuation of urban green areas. Landsc. Urban Plan. 2003, 66, 35-41. [CrossRef] 
8. Jim, C.Y.; Chen, W.Y. Impacts of urban environmental elements on residential housing prices in Guangzhou (China). Landsc. Urban Plan. 2006, 78, 422-434. [CrossRef]

9. Hamilton, J.M. Coastal landscape and the hedonic price of accommodation. Ecol. Econ. 2007, 62, 594-602. [CrossRef]

10. Kong, F.; Yin, H.; Nakagoshi, N. Using GIS and landscape metrics in the hedonic price modeling of the amenity value of urban green space: A case study in Jinan City, China. Landsc. Urban Plan. 2007, 79, $240-252$. [CrossRef]

11. Rehdanz, K.; Maddison, D. Local environmental quality and life-satisfaction in Germany. Ecol. Econ. 2008, 64, 787-797. [CrossRef]

12. Brander, L.M.; Koetse, M.J. The value of urban open space: Meta-analyses of contingent valuation and hedonic pricing results. J. Environ. Manag. 2011, 92, 2763-2773. [CrossRef]

13. Kovacs, K.F. Integrating property value and local recreation models to value ecosystem services from regional parks, Landsc. Urban Plan. 2012, 108, 79-90. [CrossRef]

14. Melichar, J.; Kaprová, K. Revealing preferences of Prague's homebuyers toward greenery amenities: The empirical evidence of distance-size effect, Landsc. Urban Plan. 2013, 109, 56-66. [CrossRef]

15. Liebelt, V.; Bartke, S.; Schwarz, N. Hedonic pricing analysis of the influence of urban green spaces onto residential prices: The case of Leipzig, Germany. Eur. Plan. Stud. 2018, 26, 133-157. [CrossRef]

16. Sylla, M.; Lasota, T.; Szewranski, S. Valuing Environmental Amenities in Peri-Urban Areas: Evidence from Poland. Sustainability 2019, 11, 570. [CrossRef]

17. Mora-Garcia, R.; Cespedes-Lopez, M.F.; Perez-Sanchez, V.R.; Marti, P.; Perez-Sanchez, J. Determinants of the Price of Housing in the Province of Alicante (Spain): Analysis Using Quantile Regression. Sustainability 2019, 11, 437. [CrossRef]

18. Ma, Y.; Gopal, S. Geographically Weighted Regression Models in Estimating Median Home Prices in Towns of Massachusetts Based on an Urban Sustainability Framework. Sustainability 2018, 10, 1026. [CrossRef]

19. Reid, W.V.; Mooney, H.A.; Cropper, A.; Capistrano, D.; Carpenter, S.R.; Chopra, K.; Dasgupta, P.; Dietz, T.; Duraiappah, A.K.; Hassan, R.; et al. Ecosystems and Human Well-Being: Synthesis-Millennium Ecosystem Assessment. 2005. Available online: http://www.millenniumassessment.org/documents/document.356.aspx. pdf (accessed on 20 December 2017).

20. Gómez-Baggethun, E.; Ruiz-Pérez, M. Economic valuation and the commodification of ecosystem services. Prog. Phys. Geogr. Earth Environ. 2011, 35, 613-628. [CrossRef]

21. Bartkowski, B. Economic Valuation of Biodiversity, 1st ed.; Routledge: London, UK, 2017. [CrossRef]

22. Czembrowski, P.; Kronenberg, J. Hedonic pricing and different urban green space types and sizes: Insights into the discussion on valuing ecosystem services. Landsc. Urban Plan. 2016, 146, 11-19. [CrossRef]

23. Wang, W.; Chang, Y.; Wang, H. An Application of the Spatial Autocorrelation Method on the Change of Real Estate Prices in Taitung City. Int. J. Geo-Inf. 2019, 8, 249. [CrossRef]

24. Id, H.W.; Jiao, H.; Yu, Y. Influence Factors and Regression Model of Urban Housing Prices Based on Internet Open Access Data. Sustainability 2018, 10, 1676. [CrossRef]

25. Weng, Y.C. Spatiotemporal changes of landscape pattern in response to urbanization. Landsc. Urban Plan. 2007, 81, 341-353. [CrossRef]

26. Yu, X.J.; Ng, N.C. Spatial and temporal dynamics of urban sprawl along two urban-rural transects: A case study of Guangzhou, China. Landsc. Urban Plan. 2007, 79, 96-109. [CrossRef]

27. Li, X.; Zhang, L.; Liang, C. A GIS-based buffer gradient analysis on spatiotemporal dynamics of urban expansion in Shanghai and its major satellite cities. Procedia Environ. Sci. 2010, 2, 1139-1156. [CrossRef]

28. McDonnell, M.J.; Hahs, A.K. The use of gradient analysis studies in advancing our understanding of the ecology of urbanizing landscapes: Current status and future directions. Landsc. Ecol. 2008, 23, 1143-1155. [CrossRef]

29. Kong, F.; Nakagoshi, N. Spatial-temporal gradient analysis of urban green spaces in Jinan, China. Landsc. Urban Plan. 2006, 78, 147-164. [CrossRef]

30. Kroll, F.; Kabisch, N. The relation of diverging urban growth processes and demographic change along an urban-rural gradient. Popul. Space Place. 2012, 18, 260-276. [CrossRef]

31. Jaganmohan, M.; Knapp, S.; Buchmann, C.M.; Schwarz, N. The Bigger, the Better? The Influence of Urban Green Space Design on Cooling Effects for Residential Areas. J. Environ. Qual. 2016, 45, 134-145. [CrossRef] 
32. Chow, W.T.L.; Pope, R.L.; Martin, C.A.; Brazel, A.J. Observing and modeling the nocturnal park cool island of an arid city: Horizontal and vertical impacts. Theor. Appl. Climatol. 2011, 103, 197-211. [CrossRef]

33. Skoulika, F.; Santamouris, M.; Kolokotsa, D.; Boemi, N. On the thermal characteristics and the mitigation potential of a medium size urban park in Athens, Greece. Landsc. Urban Plan. 2014, 123, 73-86. [CrossRef]

34. Stadt Leipzig, Bevölkerungsbestand/Population Inventory, Stat. Landesamt Des Freistaates Sachsen/Stat. State Off. Free State Saxony. 2018, pp. 1-2. Available online: https://statistik.leipzig.de/statcity/table.aspx? cat $=2 \& \mathrm{rub}=1 \&$ per $=\mathrm{q}$ (accessed on 11 May 2018).

35. Voigtländer, M. Why is the German Homeownership Rate so Low? Hous. Stud. 2009, 24, 355-372. [CrossRef]

36. Großmann, K.; Bierwirth, A.; Bartke, S.; Jensen, T.; Kabisch, S.; von Malottki, C.; Mayer, I.; Rügamer, J. Energetische Sanierung: Sozialräumliche Strukturen von Städten berücksichtigen (Energetic Retrofit: Considering Socio-spatial Structures of Cities). GAIA-Ecol. Perspect. Sci. Soc. 2014, 23, 309-312. [CrossRef]

37. Banzhaf, E.; Hoefer, R. Monitoring Urban Structure Types as Spatial Indicators With CIR Aerial Photographs for a More Effective Urban Environmental Management. IEEE J. Sel. Top. Appl. Earth Obs. Remote Sens. 2008, 1,1-14. [CrossRef]

38. Stadt Leipzig, Integriertes Stadtentwicklungskonzept Leipzig 2030/Integrated urban development concept Leipzig 2030, Leipzig. 2018. Available online: https:/www.leipzig.de/fileadmin/ mediendatenbank/leipzig-de/Stadt/02.6_Dez6_Stadtentwicklung_Bau/61_Stadtplanungsamt/ Stadtentwicklung/Stadtentwicklungskonzept/Leipzig-2030_Beschluss_Gesamtfassung.pdf (accessed on 20 December 2017).

39. R Core Team. R: A Language and Environment for Statistical Computing. R Foundation for Statistical Computing, 2017. Available online: https://www.r-project.org/ (accessed on 20 December 2017).

40. Bräuniger, C.; Knapp, S.; Kühn, I.; Klotz, S. Testing taxonomic and landscape surrogates for biodiversity in an urban setting. Landsc. Urban Plan. 2010, 97, 283-295. [CrossRef]

41. Shen, Z.; Hou, X.; Li, W.; Aini, G.; Chen, L.; Gong, Y. Impact of landscape pattern at multiple spatial scales on water quality: A case study in a typical urbanised watershed in China. Ecol. Indic. 2015, 48, 417-427. [CrossRef]

42. Grinde, A.R.; Niemi, G.J.; Sturtevant, B.R.; Panci, H.; Thogmartin, W.; Wolter, P. Importance of scale, land cover, and weather on the abundance of bird species in a managed forest. For. Ecol. Manag. 2017, 405, 295-308. [CrossRef]

43. Box, G.E.P.; Cox, D.R. An Analysis of Transformations. J. R. Stat. Soc. Ser. B 1964, 26, 211-252. [CrossRef]

44. Lutzenhiser, M.; Netusil, N.R. The effect of open spaces on a home's sale price. Contemp. Econ. Policy. 2001, 19, 291-298. [CrossRef]

45. NIST/SEMATECH, NIST/SEMATECH e-Handbook of Statistical Methods. 2013. Available online: http: //www.itl.nist.gov/div898/handbook/eda/section3/eda336.htm (accessed on 20 December 2017).

46. Osborne, J.W. Improving your data transformations: Applying the Box-Cox transformation. Pract. Assess. Res. Eval. 2010, 15, 1-9.

47. Robbins, N. When Should I Use Logarithmic Scales in My Charts and Graphs? Forbes.com, 2012. Available online: http://www.forbes.com/sites/naomirobbins/2012/01/19/when-should-i-use-logarithmic-scales-inmy-charts-and-graphs/ (accessed on 20 December 2017).

48. Crawley, M.J. The R Book; Wiley-Blackwell Publishing, Inc.: Hoboken, NJ, USA, 2007. [CrossRef]

49. Brandt, S.; Maennig, W. Perceived externalities of cell phone base stations: The case of property prices in Hamburg, Germany. Environ. Plan. A 2012, 44, 396-410. [CrossRef]

50. Tyrväinen, L. The amenity value of the urban forest: An application of the hedonic pricing method. Landsc. Urban Plan. 1997, 37, 211-222. [CrossRef]

51. Din, A.; Hoesli, M.; Bender, A. Environmental variables and real estate prices. Urban Stud. 2001, 38, 1989-2000. [CrossRef]

52. Ahlfeldt, G.M.; Maennig, W. External productivity and utility effects of city airports. Reg. Stud. 2011, 47, 508-529. [CrossRef]

53. Palmquist, R.B. Welfare measurement for environmental improvements using the hedonic model: The case of nonparametric marginal prices. J. Environ. Econ. Manag. 1988, 15, 297-312. [CrossRef]

54. Panduro, T.E.; Veie, K.L. Classification and valuation of urban green spaces-A hedonic house price valuation. Landsc. Urban Plan. 2013, 120, 119-128. [CrossRef] 
55. Bolitzer, B.; Netusil, N. The impact of open spaces on property values in Portland, Oregon. J. Environ. Manag. 2000, 59, 185-193. [CrossRef]

56. Larson, E.K.; Perrings, C. The value of water-related amenities in an arid city: The case of the Phoenix metropolitan area. Landsc. Urban Plan. 2013, 109, 45-55. [CrossRef]

57. Liebelt, V.; Bartke, S.; Schwarz, N. Revealing Preferences for Urban Green Spaces: A Scale-sensitive Hedonic Pricing Analysis for the City of Leipzig. Ecol. Econ. 2018, 146, 536-548. [CrossRef]

(C) 2019 by the authors. Licensee MDPI, Basel, Switzerland. This article is an open access article distributed under the terms and conditions of the Creative Commons Attribution (CC BY) license (http://creativecommons.org/licenses/by/4.0/). 